\title{
Shear wave elastography in assessment of liver stiffness and prediction of gastro- esophageal varices in patients with liver cirrhosis
}

\author{
Mohammed Zaki ${ }^{*}$, Mohammed Hazem ${ }^{1}$ and Mahmoud Elsamman ${ }^{2}$
}

\begin{abstract}
Background: Shear wave elastography is an ultrasound applied technique used to measure tissue stiffness as a result of a disease. So, it can be used to evaluate liver stiffness as a result of liver cirrhosis and could correlate it with esophageal varices. The purpose of this study was to evaluate the efficiency of shear wave elastography for assessment of liver stiffness and predicting the presence of gastro-esophageal varices in patients with liver cirrhosis.

Results: Ultrasound liver changes were seen in $100 \%$ of the included patients. Color Doppler revealed portosystemic collaterals in $20 \%$ patients. Shear wave elastography could differentiate cases from control with cutoff value of $13.1 \mathrm{kPa}$. There was a significant correlation between shear wave elastography and ultrasound changes in cirrhotic patients. Endoscopy found more number of esophageal (44\%) and gastric varices (10\%) as liver stiffness increase. Gastro-esophageal varices are detected in 32 (53.33\%) cirrhotic patients. Shear wave elastography could predict presence of gastro-esophageal varices in cirrhotic patients with a cutoff value of $26.5 \mathrm{kPa}$ and sensitivity of $88 \%$ and specificity of $85 \%$.
\end{abstract}

Conclusion: Shear wave elastography is an important non-invasive radiological method for assessment of liver stiffness and prediction of the presence of gastro-esophageal varices in cirrhotic patients.

Keywords: Shear wave elastography, Liver cirrhosis, Gastro-esophageal varices

\section{Background}

Chronic hepatitis $\mathrm{C}$ virus is endemic in Egypt, with high morbidity and mortality rate from cirrhosis and its complications [1-3].

Early detection of cirrhosis by detection of fibrosis is a key element to manage treatment, monitor disease progression, assess response to therapy, and determine prognosis in chronic hepatitis $\mathrm{C}$ patients. Biopsy and histopathological assessment remains the standard of reference to evaluate liver fibrosis. However, this procedure is painful and has many complications as hemorrhage $(0.3 \%)$ or death $(0.01 \%)$. Also, biopsy analysis

\footnotetext{
* Correspondence: zakifm2000@yahoo.com

${ }^{1}$ Department of Radiology, Sohag Faculty of Medicine, Sohag University, Sohag, Egypt

Full list of author information is available at the end of the article
}

depends on the size of the biopsy sample, the site of sampling, and the experience of the pathologist $[4,5]$.

Liver cirrhosis is known to lead to portal hypertension and metabolic hepatic failure. The number of cirrhotic patients has been observed to be growing, along with the increased incidence of hepatitis $C$ virus infections and increased detection of nonalcoholic fatty liver disease and nonalcoholic steatohepatitis [6, 7].

The most serious consequences of chronic liver disease is portal hypertension and results to progressive liver fibrogenesis. It can lead to the development of ascites, gastro-esophageal varices, and encephalopathy. It causes a significant increase in mortality [8].

Development of gastro-esophageal varices is one of the major complications of portal hypertension; it occurs in approximately $30-70 \%$ of patients with cirrhosis and is correlated with the severity of liver disease $[9,10]$. 

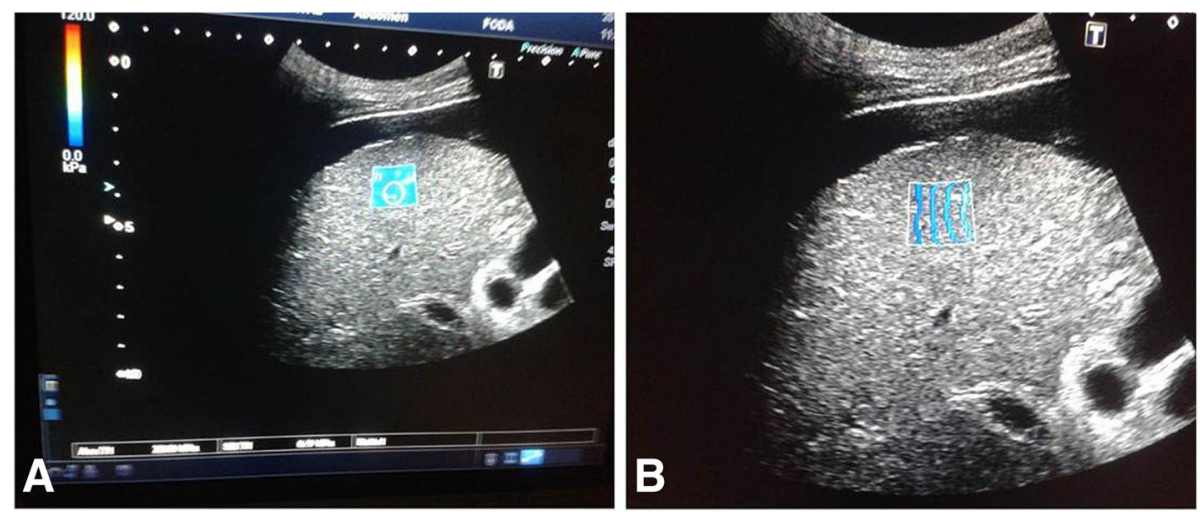

Fig. 1 a, b Shear wave elastography images showing typical box of elastography measurement

Considering that the mortality rate of variceal bleeding remains high, screening endoscopy for gastro-esophageal varices is recommended for all patients with established cirrhosis. Esophagogastroduodenoscopy (EGD) is the golden accurate diagnostic procedure to predict varices, and therapeutic intervention can be made at the same time. Moreover, EGD is an accurate procedure that can detect other risk stigmata for variceal bleeding such as a red color sign and the size of the varices $[11,12]$. Unfortunately, endoscopy is expensive, invasive, and uncomfortable and frequently requires sedation. Therefore, there is a clinical need for a non-invasive and sensitive method to assess gastro-esophageal varices, particularly high-risk varices [13].

A new technique developed recently is shear wave elastography (SWE); this technique is based on shear waves that has been implemented in diagnostic ultrasound (US) systems. Like transient elastography, SWE estimates the speed of shear waves to provide a quantitative estimate of tissue stiffness. However, transient elastography has limitations and a failure rate approaching up to 19\% [14]. But SWE has the advantage of being able to image liver tissue stiffness in real time because the shear waves are generated by US impulses. Moreover, SWE imaging is guided using B-mode images with a higher frame rate. This method can provide more accurate assessment of liver tissue stiffness due to the advantages of SWE and B-mode image guidance [15].

The aim of this study is to evaluate the use of SWE in predicting gastro-esophageal varices by measuring liver stiffness and comparing it with endoscopic examination.

\section{Methods}

This prospective study was conducted in Sohag University Hospital, Faculty of Medicine, Sohag University, during the period from July 2016 to December 2018.

The study included 60 cirrhotic patients and 20 healthy volunteers, aged >18 years, who accepted participation in this study. Exclusion criteria included
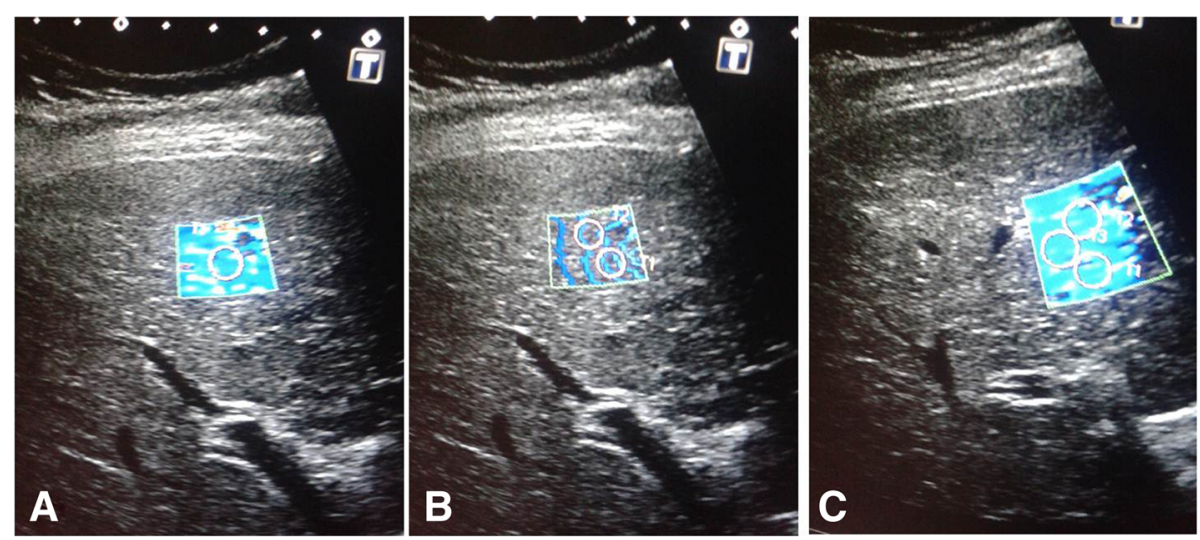

Fig. 2 a Single Roi circle of stiffness measurement. b Two Roi circles of stiffness measurement. c Three circles of stiffness measurements 
presence of hepatic encephalopathy grade 3 or grade 4, left-sided portal hypertension (this entity is due to pancreatic disease with normal liver), presence of a contraindication to perform upper gastrointestinal endoscopy (EGD), or presence of hepatocellular carcinoma. Patients with advanced cardiac, renal, or pulmonary disease were also excluded. Diagnosis of liver cirrhosis was based upon clinical evaluation, liver function tests, abdominal ultrasonography, and hepatitis markers or PCR. All volunteers were healthy and free from any disease affecting the liver.

All patients and control volunteers were subjected to abdominal ultrasound examination, Doppler examination, and real-time Shear wave elastography using (Toshiba Aplio 500) at our Radiology Department. All cirrhotic patients were subjected to EGD at the endoscopy unit of the Internal Medicine Department.

The current study was approved by the Institutional Committee in our University Faculty of Medicine. Written informed consent was obtained from all patients and volunteers.

\section{Shear wave elastography (SWE)}

The patient is placed in a supine position with the right arm placed in maximum abduction to enlarge the space between the ribs. The convex probe is placed between the ribs, using the best acoustic window available for liver evaluation. The SWE box has to be placed in a uniform zone, away from the sub-capsular region to avoid reverberation artifacts that are often found beneath the capsule (Fig. 1). Similarly, perivascular areas were avoided because they may alter liver stiffness estimate. The patient has to hold breath in the expiration phase to acquire a stable image. The color map is not dependable to assess liver stiffness because it is operator dependent and not quantitative. So, we depended on liver stiffness measurement in $\mathrm{kPa}$.

The elastography acquisition was repeated three to five times for each patient. For each acquisition, real-time SWE 2D color map of the stiffness (in $\mathrm{kPa}$ ) was frozen after a stabilization of at least $3 \mathrm{~s}$. The size of the SWE color box was about $3 \times 4 \mathrm{~cm}$. The measurements were performed in a 1.6- to 3 -cm-diameter region of interest (ROI) (Fig. 2). For each patient, stiffness was defined as the median of several SWE successful measurements.

\section{Upper gastrointestinal endoscopy (EGD) protocol}

Upper GIT endoscopy (EGD) was performed after overnight fasting under conscious sedation and nasal oxygen using EG-2985 scope, Pentax, Tokyo, Japan. Patients were placed in the left lateral position, and the endoscope was inserted into the esophagus and passed to the stomach down to the second part of the duodenum.

Endoscopic findings of esophageal varices (EV) and gastric varices (GV) were classified according to the criteria proposed by the Japanese Society for Portal Hypertension [16]. The form (F) of GV or EV was classified as straight small-calibered varices (F1); moderately enlarged, beady varices (F2); or markedly enlarged, nodular, or tumor-shaped varices (F3). According to location, EV were classified as varices at

Table 1 Clinical and laboratory data of the 60 included cirrhotic patients

\begin{tabular}{|c|c|}
\hline Variables & Summary statistics \\
\hline \multicolumn{2}{|l|}{ Age } \\
\hline Mean $\pm \mathrm{SD} /$ median (range) & $54.12 \pm 10.53 / 55.5(23-73)$ \\
\hline \multicolumn{2}{|l|}{ Gender } \\
\hline Females/males & $12(20 \%) / 48(80 \%)$ \\
\hline \multicolumn{2}{|l|}{ Cause of liver cirrhosis } \\
\hline $\mathrm{HBV} / \mathrm{HCV}$ & $5(8.33 \%) / 48(80 \%)$ \\
\hline $\mathrm{HBV}$ and $\mathrm{HCV} /$ others & $0(0 \%) / 7(11.66 \%)$ \\
\hline \multicolumn{2}{|l|}{ Child Pugh score } \\
\hline Child A/child B/child C & 15(25\%)/23(38.33\%)/22(36.66\%) \\
\hline \multicolumn{2}{|l|}{ WBCs $\left(\times 10^{9} / \mathrm{l}\right)$} \\
\hline Mean $\pm \mathrm{SD} /$ median (range) & $13.45 \pm 1.39 / 13(10.5-17)$ \\
\hline \multicolumn{2}{|l|}{ Hemoglobin (gm/dl) } \\
\hline Mean \pm SD/median (range) & $9.38 \pm 2.16 / 9(8-14.2)$ \\
\hline \multicolumn{2}{|l|}{ Platelet count $\left(\times 10^{9} / \mathrm{I}\right)$} \\
\hline Mean \pm SD/median (range) & $112.55 \pm 54.71 / 86(30-412)$ \\
\hline \multicolumn{2}{|l|}{ ALT (IU/L) } \\
\hline Mean $\pm \mathrm{SD} /$ median (range) & $38.86 \pm 58.06 / 35(18-89)$ \\
\hline \multicolumn{2}{|l|}{ Serum Albumin (g/dl) } \\
\hline Mean \pm SD/median (range) & $2.19 \pm 0.53 / 2.0(1.8-4.4)$ \\
\hline \multicolumn{2}{|l|}{ Direct bilirubin (mg/dl) } \\
\hline Mean \pm SD/median (range) & $2.73 \pm 2.15 / 2(0.1-13.34)$ \\
\hline \multicolumn{2}{|l|}{ INR } \\
\hline Mean $\pm \mathrm{SD} /$ median (range) & $1.76 \pm 0.71 / 1.55(0.97-4.98)$ \\
\hline \multicolumn{2}{|l|}{ Splenomegaly } \\
\hline No/mild/moderate/huge & $14(23.3 \%) / 20(33.3 \%) / 26(43.3 \%) / 0 \%$ \\
\hline \multicolumn{2}{|l|}{ Ascites } \\
\hline No/mild/moderate/marked & $\begin{array}{l}15(25 \%) / 13(21.66 \%) / 20(33.3 \%) / \\
12(20 \%)\end{array}$ \\
\hline \multicolumn{2}{|l|}{ Liver changes by U/S } \\
\hline $\begin{array}{l}\text { Minimal to moderate/ } \\
\text { shrunken }\end{array}$ & 18(30\%)/42 (70\%) \\
\hline \multicolumn{2}{|l|}{ Presence of varices in EGD } \\
\hline Present/absent & $32(53.33 \%) / 28(46.66 \%)$ \\
\hline
\end{tabular}

$H B V$ hepatitis $B$ virus, $H C V$ hepatitis $C$ virus, WBCs white blood cells count, $A L T$ alanine aminotransferase, INR International Normalized Ratio, U/S abdominal ultrasonography, EGD, upper gastrointestinal endoscopy 


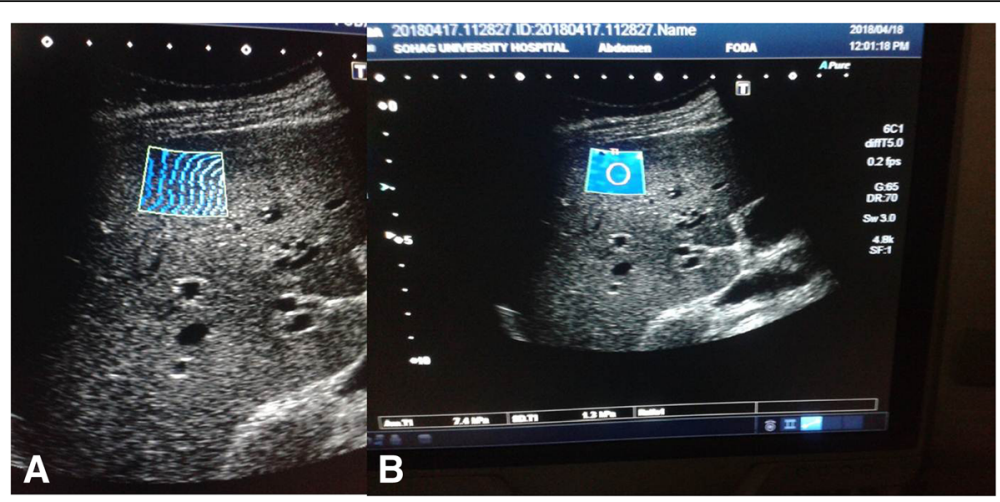

Fig. 3 a, b Shear wave elastography images of a normal 35-year-old healthy control male patient showing liver stiffness of $7.4 \mathrm{KPa}$

the lower $1 / 3$ of the esophagus (Li), at the middle $1 / 3$ of the esophagus $(\mathrm{Lm})$, or at the upper $1 / 3$ of the esophagus (Ls). According to location, GV were classified as adjacent to the cardiac orifice (Lg-c), distant from the cardiac orifice (Lg-f), or extending from the cardiac orifice to the fornix (Lg-cf). Varices were also classified according to its bluish $(\mathrm{Cb})$ or whitish $(\mathrm{Cw})$ color and if the varices were associated with red color sign (RC) or not. All endoscopic procedures were performed by a single operator with 10 years of experience in endoscopic management of gastro-esophageal varices. Endoscopic management of the detected varices was performed according to guideline recommendations.

\section{Statistical analysis}

The analysis of data was made using SPSS version 16. Continuous data were expressed. Quantitative data was represented as mean, standard deviation, median, and range. $P$ value was considered significant if it was less than 0.05 .

\section{Results}

Clinical characteristic of the patients:

The study involved 60 cirrhotic patients. Male patients were $80 \%$. Age range was 23 to 73 years. The healthy control volunteers included 20 persons with $75 \%$ being male and age range from 21 to 63 years. The etiology of liver cirrhosis was HBV in 5 (8.33\%) patients and $\mathrm{HCV}$ in $80 \%$ patients. The remaining patients were negative for $\mathrm{HCV}$ and HBV. Child Pugh score and other base line clinical and laboratory data of the cirrhotic patients were shown in Table 1.

By abdominal ultrasound, a shrunken liver was seen in 18 patients $(30 \%)$ while other patients had minimal to moderate changes. Portal vein diameter was dilated in about $75 \%$ of cases $(12-17 \mathrm{~mm})$ with decreased peak systolic velocity. As regards the spleen, splenomegaly was seen in over $76 \%$ of cases, most of them were moderate splenomegaly, and about $10 \%$ show mild splenomegaly with no case having huge splenomegaly. Ascites was present in 45 cirrhotic patients. Porto-systemic collaterals were found in 12 patients by color Doppler.

\section{Endoscopic findings}

Upper GIT endoscopy showed presence of gastroesophageal varices in 32 cirrhotic patients. Esophageal varices were detected in 26 patients, and 6 patients showed presence of gastric varices. The form of EV was F1 in 10 patients, F2 in 6 patients, and F3 in the remaining 10 patients. No EV could be detected in 28 cirrhotic patients. The form of GV was F1 in 2 patients, F2 in 1 patient, and F3 in 3 patients. EV with high-risk stigmata received endoscopic variceal ligation, while large-sized GV (F3) underwent cyanoacrylat injection.

\section{Real-time shear wave elastography findings}

By analyzing the shear wave elastography findings in cases and comparing it with those of the control group (Fig. 3), we found that SWE was significantly higher among cases compared to controls (Table 2) with a cutoff value of $13.1 \mathrm{kPa}$ and sensitivity and specificity of $100 \%$.

Shear wave elastography shows increased liver stiffness in cirrhotic patients $(13.1-58 \mathrm{kPa})$ (Figs. 4, 5, 6, 7 , and 8). SWE could also differentiate between cirrhotic patients with gastro-esophageal varices and patients without gastro-esophageal varices with a cutoff value of $26.5 \mathrm{kPa}$ and sensitivity of $88 \%$ and specificity

Table 2 SWE (in $\mathrm{kPa}$ ) in cases and controls

\begin{tabular}{llllll}
\hline & Group & $N$ & Mean & Std. deviation & Std. error mean \\
\hline Shear wave & Case & 60 & 45.650 & 10.5413 & 2.1172 \\
& Control & 20 & 10.400 & 2.6591 & 1.1471
\end{tabular}

$T$ test $=10.404, p$ value $<0.001$ 


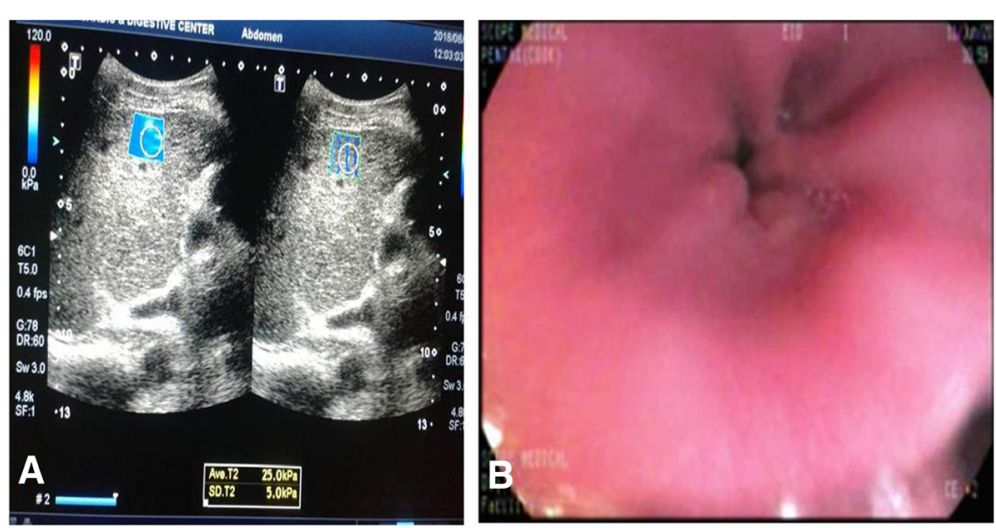

Fig. 4 A 38-year-old female patient with chronic hepatitis C virus and early cirrhotic changes. a Shear wave elastography images showing liver stiffness of $25.0 \mathrm{KPa}$. b Endoscopy image shows normal esophageal mucosa without varices

of $85 \%$. SWE also found that as liver stiffness increase, the more is the increase in the size of the varices (47.3-49.5 kPa in F3), Tables 3 and 4).

\section{Discussion}

Liver cirrhosis is a major health problem in Egypt, especially in Sohag Governorate. So, detection of the sequelae of this disease, namely fibrosis and varices, are very important to decrease the morbidity and mortality of this disease entity $[1,2,17,18]$.

Non-invasive methods are used to detect fibrosis such as transient elastography but it was not so accurate and has limitations in obesity and ascites. By now, real-time shear wave elastography was used to detect the degree of liver stiffness due to fibrosis which is resulted from liver injury by virus. So, there is a decrease in the need for an invasive method such as liver biopsy [19]. As far as the hepatic fibrosis is increased, portal hypertension is increased, and so, esophageal and gastric varices resulted.
Esophageal and gastric varices are serious complications of liver cirrhosis and may lead to increase mortality rate. Upper GIT endoscopy is the golden standard method for diagnosis of EV and GV. Endoscopic screening for all patients with liver cirrhosis at the time of their diagnosis is recommended, and periodic endoscopic examination of the patients with EV is also recommended [20]. EGD can be considered an invasive and uncomfortable procedure which may not be acceptable by some patients. Moreover, routine endoscopy screening could not be cost-effective [21]. Therefore, predicting the presence of gastroesophageal varices through non-endoscopic and noninvasive procedures is an important issue to identify the cirrhotic patients who benefit from endoscopic screening and to reduce unnecessary endoscopic procedures [22].

So, measurement of liver stiffness can detect portal hypertension and may predict esophageal varices. Our study was carried out to measure liver stiffness and
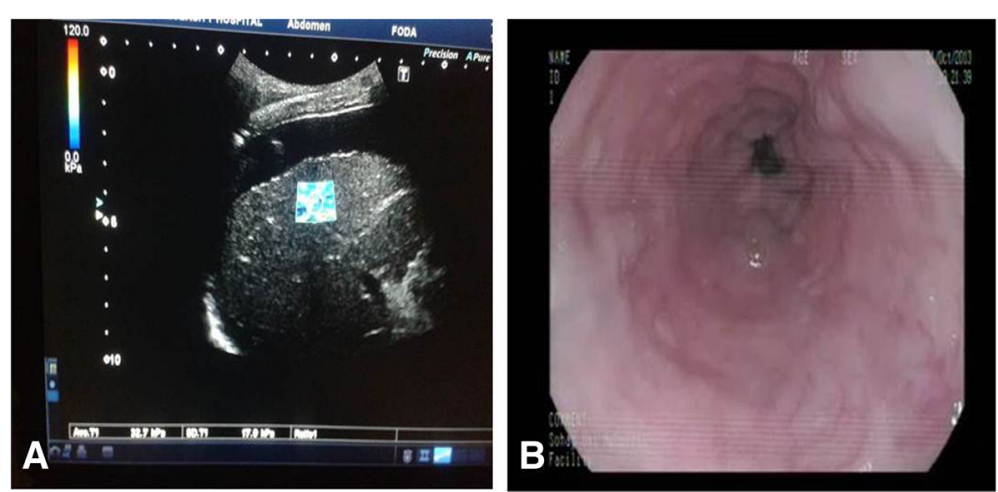

Fig. 5 A 63-year-old male patient. a Shear wave elastography image showing liver stiffness of $32 \mathrm{KPa}$. b Endoscopy image showing esophageal varices located at the middle $1 / 3$ of the esophagus $(\mathrm{Lm})$, small in size (F1), whitish in color (CW), with no red color sign (RC-ve) 


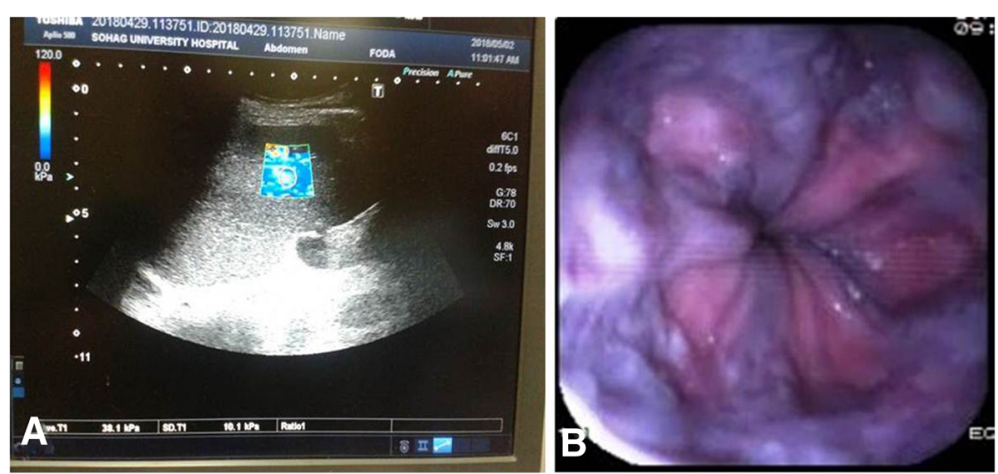

Fig. 6 A 6-year-old male patient presented with hematemesis. a Shear wave elastography image showing liver stiffness of 38 KPa. b Endoscopy image showing esophageal varices located at the lower $1 / 3$ of the esophagus (Li), medium size (F2), bluish in color (Cb) with positive red color sign $(\mathrm{RC}+\mathrm{ve})$

compare it with endoscopic findings to predict esophageal and gastric varices.

Our study included 60 patients with liver cirrhosis and 20 normal controls. The majority of the patients were males. Mohamed RE et al. [19] examined 60 patients with elastography, 38 of them were males. Real-time shear wave elastography were done to all patients and control. Mean liver stiffness was high in patients in comparison to controls (28 and $3 \mathrm{kPa}$, respectively). This difference was also found in literatures. Mohamed et al. [19] found liver stiffness is high in patients with highgrade fibrosis $(12.6 \mathrm{kPa})$ than in controls $(3.1 \mathrm{kPa})$.

There was a significant correlation between abnormal laboratory data and increase liver stiffness in our study. There was also a significant correlation between degree of splenomegaly and degree of liver stiffness at real-time shear wave elastography. As the liver stiffness increased, there was an increase in the size of the spleen. As the spleen size increased, there was more chance to find varices [23]. Moderate splenomegaly was found in our study in $26 \%$ of patients. Tag-Aden et al. [24] found that spleen size over $15 \mathrm{~cm}$ is a complementary predictor of varices.

In patients without varices, the liver stiffness range was $15-25 \mathrm{kPa}$. Hashim et al. [25] reported liver stiffness in the range of $14-36.1 \mathrm{kPa}$ in cirrhotic patients without EV. As the liver becomes more stiff and cirrhotic, there is an increase of portal hypertension and a detection of esophageal and gastric varices by endoscopy. Liver stiffness at real-time shear wave elastography was above 25 $\mathrm{kPa}$ in patients with varices. Endoscopy detects different grades of varices from early to advanced varices, even
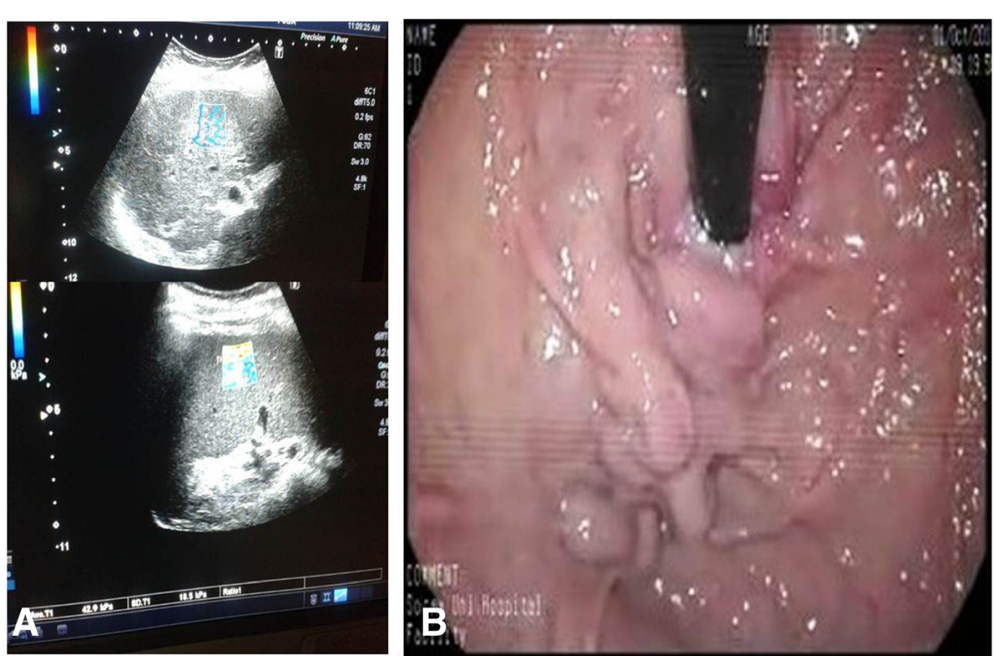

Fig. 7 A 45-year-old female patient with liver cirrhosis. a Shear wave elastography image showing liver stiffness of $42 \mathrm{KPa}$. b Endoscopy image showing gastric varices located at the cardia and extended to the fundus (Lg-Cf), medium in size (F2), and whitish in color (CW) with no red color sign (RC-ve) 

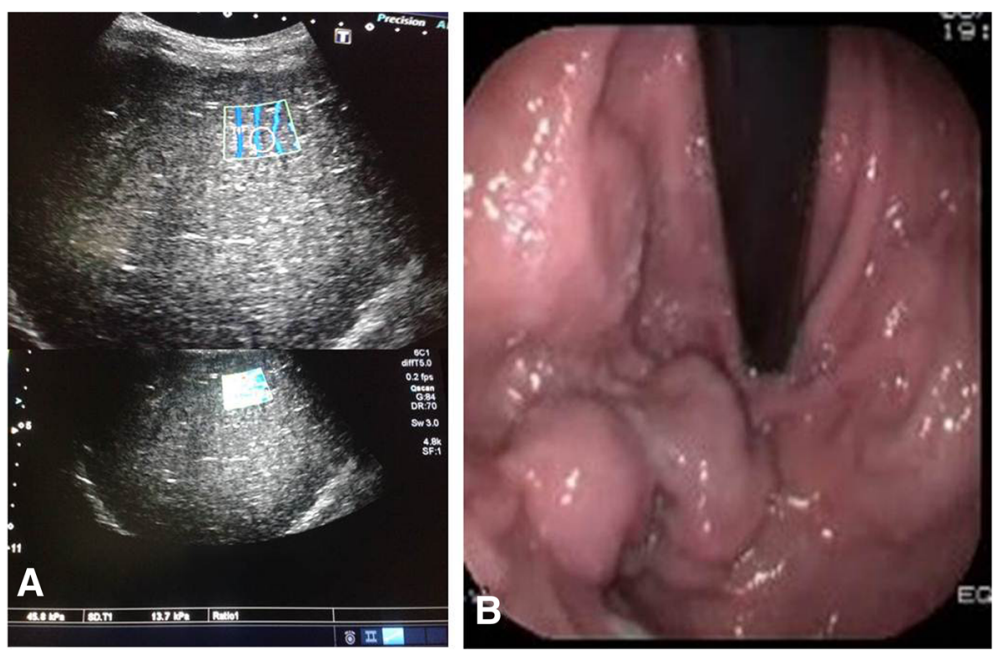

Fig. 8 A 58-year-old male patient with cirrhosis. a Shear wave elastography image showing liver stiffness of $45 \mathrm{KPa}$. b Endoscopy image showing isolated gastric varices located at the fundus (Lg-f), large in size (F3), and whitish in color (CW) with no red color sign (RC-ve)

varices with risk of bleeding. There was a marked increase in liver stiffness in those patients with large and risky varices. Many previous studies [26-28] are going with our study and tested the use of non-invasive methods to predict gastro-esophageal varices including spleen size, platelet count, platelet count/spleen diameter ratio, transient elastography, and shear wave elastography of the liver. These studies recommended the use of shear wave elastography as a good predictor for gastro-esophageal varices to avoid the frequent endoscopic evaluation. However, there were differences in the number of kilopascal in cirrhotic patients with esophageal varices in our study as compared with these previous studies. In our results, SWE range was $26-58 \mathrm{kPa}$ by Toshiba, Aplio machine. Kim et al. [27] reported SWE range of 13.1-30.3 kPa. Elkrief et al.'s [28] SWE range was $16.1-38 \mathrm{kPa}$. Both reports used the same machine
(Aixplorer, Supersonic Imagine ultrasound system). We attributed these differences to the machine used (different manufacturers have different values) as stated in the European Federation of Societies for Ultrasound in Medicine and Biology guidelines [29].

Our study has some limitations: firstly, the small number of included patients and lack of follow-up to detect progression of liver stiffness in cirrhotic patients; secondly, the lack of comparison with other non-invasive radiological methods for assessment of liver stiffness like fibroscan; and, lastly, the lack of assessment of the role of SWE as a predictor of morbidity and mortality in patients with liver cirrhosis. This work is in need for further extension and research on a larger scale. However, our study is the first study in our locality that refers and highlights the importance of use of real-time SWE as a non-invasive method for the assessment of liver

Table 3 Relation between SWE (in kPa) and endoscopic findings

\begin{tabular}{|c|c|c|c|c|c|c|c|}
\hline & EGD & & & Mean & SD & ANOVA & $P$ value \\
\hline \multirow[t]{4}{*}{ SWE } & EV & Form & $1 / 2 / 3$ & $38.2 / 42.5 / 47.3$ & $3.7 / 19.2 / 12.8$ & 4.122 & 0.034 \\
\hline & & Location & Lm/Ls/Li & 43.2/48.8/46.3 & $12.5 / 11.7 / 10.2$ & 6.708 & 0.021 \\
\hline & & Color & $\mathrm{Cb} / \mathrm{Cw}$ & $38.1 / 47.3$ & $12.2 / 11.4 / 10.8$ & 6.884 & 0.027 \\
\hline & & $\mathrm{RC}$ & $+/++$ & $43.4 / 46.5$ & 11.9/13.1/15.6 & 1.678 & 0.052 \\
\hline \multirow[t]{5}{*}{ SWE } & GV & & & & & & \\
\hline & & $\operatorname{Lg}$ & $C / F / C-F$ & $41.5 / 44.5 / 45$ & $2.1 / 2.3 / 1.8$ & 3.120 & 0.043 \\
\hline & & Form & $1 / 2 / 3$ & $33.1 / 46.1 / 49.5$ & $12.4 / 9.8 / 29.2$ & 3.332 & 0.029 \\
\hline & & Color & $\mathrm{Cb} / \mathrm{Cw}$ & $46.5 / 48.3$ & $4.3 / 5.6$ & 4.102 & 0.023 \\
\hline & & $\mathrm{RC}$ & $-/+$ & $31.4 / 48.3$ & $11.8 / 5.1$ & 7.328 & 0.006 \\
\hline
\end{tabular}

$E G D$ upper GIT endoscopy, SD standard deviation, SWE real-time shear wave elastography, EV esophageal varices, GV gastric varices, $R C$ red color sign, $C b$ bluish in color, $\mathrm{C} w$ whitish in color 
Table 4 Relation between SWE (in $\mathrm{kPa}$ ) and gastro-esophageal varices

\begin{tabular}{|c|c|c|c|c|c|c|c|}
\hline & & Number & Mean & Std. deviation & Std. error mean & $T$ test & $P$ value \\
\hline \multirow[t]{2}{*}{ SWE } & EV & & & & & & \\
\hline & $\begin{array}{l}\text { Present } \\
\text { Absent }\end{array}$ & $\begin{array}{l}26 \\
34\end{array}$ & $\begin{array}{l}51.759 \\
28.275\end{array}$ & $\begin{array}{l}11.7747 \\
13.1624\end{array}$ & $\begin{array}{l}2.7939 \\
2.6547\end{array}$ & 6.717 & 0.022 \\
\hline \multirow[t]{2}{*}{ SWE } & GV & & & & & & \\
\hline & $\begin{array}{l}\text { Present } \\
\text { Absent }\end{array}$ & $\begin{array}{l}6 \\
54\end{array}$ & $\begin{array}{l}49.657 \\
32.083\end{array}$ & $\begin{array}{l}21.2185 \\
11.4386\end{array}$ & $\begin{array}{l}11.8625 \\
10.0108\end{array}$ & 2.032 & 0.51 \\
\hline
\end{tabular}

SWE real-time shear wave elastography, EV esophageal varices, GV gastric varices

stiffness and to predict the presence of gastro-esophageal varices in cirrhotic patients.

\section{Conclusion}

Real-time shear wave elastography is an important noninvasive method to assess liver fibrosis and to predict the presence of gastro-esophageal varices in cirrhotic patients. Further larger studies are required to clarify the potential role of SWE in management of liver cirrhosis and its complications.

\section{Abbreviations}

SWE: Shear wave elastography; US: Ultrasound; GV: Gastric varices;

EV: Esophageal varices; EGD: Esophagogastroduodenoscopy

\section{Acknowledgements}

Not applicable

\section{Availability of data and material}

The datasets used and/or analyzed during the current study are available from the corresponding author.

\section{Authors' contributions}

ZM and HM carried out the manuscript writing and design and radiological examinations. EM carried out the manuscript writing and design and endoscopic examinations. All authors read and approved the final manuscript.

\section{Funding}

Not applicable

\section{Ethics approval and consent to participate}

The current study was approved by our Institutional Committee in Sohag University Faculty of Medicine. Written informed consent was obtained from all patients and volunteers.

\section{Consent for publication}

Written informed consents were taken from all patients parents without identifying the privacy of the patients.

\section{Competing interests}

The authors declare that they have no competing interests

\section{Author details}

'Department of Radiology, Sohag Faculty of Medicine, Sohag University, Sohag, Egypt. ${ }^{2}$ Gastroenterology Division, Internal Medicine Department, Sohag Faculty of Medicine, Sohag University, Sohag, Egypt.
Received: 4 June 2019 Accepted: 22 July 2019

Published online: 06 September 2019

References

1. Kamel MA, Ghaffar YA, Wasef MA, Wright M, Clark LC, Miller FD (1992) High HCV prevalence in Egyptian blood donors. Lancet 15(340):427

2. Abdel-Wahab MF, Zakaria S, Kamel M et al (1994) High seroprevalence of hepatitis C infection among risk groups in Egypt. Am J Trop Med Hyg 51: 563-567

3. Poynard T, Lebray P, Ingiliz P et al (2010) Prevalence of liver fibrosis and risk factors in a general population using non-invasive biomarkers (FibroTest). BMC Gastroenterol 10:40

4. Dohan A, Guerrache Y, Boudiaf M, Gavini JP, Kaci R, Soyer P et al (2014) Transjugular liver biopsy: indications, technique and results. DiagnInterv Imaging 95:11-15

5. Guibal A, Renosia G, Rodec A et al (2016) Shear wave elastography: an accurate technique to stage liver fibrosis in chronic liver diseases. Diagnostic and Interventional Imaging 97:91-99

6. Vuppalanchi R, Chalasani N (2009) Nonalcoholic fatty liver disease and nonalcoholic steatohepatitis: selected practical issues in their evaluation and management. Hepatology 49(1):306-317

7. Michitaka K, Nishiguchi S, Aoyagi Y. et al (2010) Etiology of liver cirrhosis in Japan: a nationwide survey. J. Gastroenterol 45 (1):86-94

8. Catherine Lucero, and Robert S. Brown, Jr. (2016) Non-invasive measures of liver fibrosis and severity of liver disease. GastroenterolHepatol (N Y) Jan; 12 (1): $33-40$

9. Merli M, Nicolini G, Angeloni S, et al (2003) Incidence and natural history of small esophageal varices in cirrhotic patients. J Hepatol 38(3):266-272

10. Bosch J, Berzigotti A, Garcia-Pagan JC, Abraldes JG (2008) The management of portal hypertension: rational basis, available treatments and future options. J Hepatol 48 (Suppl 1:S68-S92

11. Garcia-Tsao G, , Sanyal AJ, , Grace ND and Carey W. (2007) Practice Guidelines Committee of the American Association for the Study of Liver Diseases; Practice Parameters Committee of the American College of Gastroenterology. Prevention and management of gastroesophageal varices and variceal hemorrhage in cirrhosis. Hepatology 46 (3) : 922-938

12. De Franchis R (2005) Evolving consensus in portal hypertension. Report of the Baveno IV consensus workshop on methodology of diagnosis and therapy in portal hypertension. J Hepatol 43(1):167-176

13. Shin SU, Lee J-M, Yu MH et al (2014) Prediction of esophageal varices in patients with cirrhosis: usefulness of three-dimensional MR elastography with echo-planar imaging technique. Radiology July 272(1):143-153

14. European Association for Study of Liver; Associacion Latinoameri-canapara el Estudio del Higado EASL-ALEH clinical practice guidelines (2015) non-invasive tests for evaluation of liver disease severity and prognosis. J Hepatol 63:237-264

15. Yoshitaka K, Fuminori M, Kazuhiro S et al (2015) Value of shear wave elastography for predicting hepatocellular carcinoma and esophagogastric varices in patients with chronic liver disease. J Med Ultrasonics 42:349-355

16. Idezuki Y (1995) General rules for recording endoscopic findings of esophagogastric varices (1991). Japanese Society for Portal Hypertension. World J Surg 19:420-422

17. Darwish MA, Raouf TA, Rushdy P, Constantine NT, Rao MR, Edelman R (1993) Risk factors associated with a high seroprevalence of hepatitis $C$ virus infection in Egyptian blood donors. Am J Trop Med Hyg 49:440-447 
18. Waked IA, Saleh SM, Moustafa MS, Raouf AA, Thomas DL, Strickland GT (1995) High prevalence of hepatitis C in Egyptian patients with chronic liver disease. Gut 37:105-107

19. Mohamed RE, Amin MA, Omar HM, Rabea MY, AbdElazeem MA (2017) Quantitative assessment of liver fibrosis in chronic viral hepatitis C patients using shear wave elastography with elastography point quantification feature. Egypt J Radiol Nucl Med 48(1):31-42

20. de Franchis R (2015) Expanding consensus in portal hypertension: report of the Baveno VI Consensus Workshop: stratifying risk and individualizing care for portal hypertension. J Hepatol 63:743-752

21. Garcia-Tsao G, Sanyal AJ, Grace ND, Carey WD (2007) Prevention and management of gastro-esophageal varices and variceal hemorrhage in cirrhosis. Am J Gastroenterol 102:2086-2102

22. de Franchis R (2006) Noninvasive diagnosis of esophageal varices: is it feasible? Am J Gastroenterol 101:2520-2522

23. Berzigotti A, Seijo S, Arena U et al (2013) Elastography, spleen size, and platelet count identify portal hypertension in patients with compensated cirrhosis. Gastroenterology 144:102-111.e1

24. Tag-Adeen M, Alsenbesy M, Ghweil AA et al (2017) Liver stiffness measurement and spleen diameter as predictors for the presence of esophageal varices in chronic hepatitis C patients. Medicine (Baltimore) 96(46):e8621

25. Hashim AEM, Shakweer MM, Attia FF et al (2017) Measurement of liver and spleen stiffness by shear wave elastography as a noninvasive evaluation of esophageal varices in hepatitis C virus-related cirrhosis. Al-Azhar Assiut Medical Journal 15(2):111-116

26. Berzigotti A, Bosch J, Boyer TD (2014) Use of noninvasive markers of portal hypertension and timing of screening endoscopy for gastro-esophageal varices in patients with chronic liver disease. Hepatology 59:729-731

27. Kim TY, Kim TY, Kim Y et al (2016) Diagnostic performance of shear wave elastography for predicting esophageal varices in patients with compensated liver cirrhosis. J Ultrasound Med 35:1373-1381

28. Elkrief $\mathrm{L}$, Ronot $\mathrm{M}$, Andrade $\mathrm{F}$ et al (2018) Non-invasive evaluation of portal hypertension using shear wave elastography: analysis of two algorithms combining liver and spleen stiffness in 191 patients with cirrhosis. Aliment PharmacolTher 47:621-630

29. Dietrich CF, Bamber J, Berzigtti A et al (2017) EFSUMB guidelines and recommendations on the clinical use of liver ultrasound elastography, Update 2017 (Long Version). Ultraschall Med 38:e16-e47

\section{Publisher's Note}

Springer Nature remains neutral with regard to jurisdictional claims in published maps and institutional affiliations.

\section{Submit your manuscript to a SpringerOpen ${ }^{\circ}$ journal and benefit from:}

- Convenient online submission

- Rigorous peer review

- Open access: articles freely available online

- High visibility within the field

- Retaining the copyright to your article

Submit your next manuscript at $\boldsymbol{\nabla}$ springeropen.com 